\title{
ANALISIS PENGENDALIAN KUALITAS PRODUK MENGGUNAKAN METODE STATISTICAL QUALITY CONTROL (SQC) PADA DIVISI CURING PLANT D PT. GAJAH TUNGGAL, Tbk
}

\author{
PUJI RAHAYU' ${ }^{1)}$ \& JOKO SUPONO ${ }^{2)}$ \\ 1,2) Teknik Industri, Universitas Muhammadiyah Tangerang \\ e-mail: puji.umt16@gmail.com; joko.supono@yahoocom
}

\begin{abstract}
ABSTRAK
PT. Gajah Tunggal Tbk, merupakan produsen ban mobil dan sepeda motor yang selalu berusaha meningkatkan produktivitas produksi guna memenuhi permintaan customer-customer dari perusahaan otomotif. Berdasarkan data yang di dapat dari PT. Gajah Tunggal Tbk., problem yang paling mempengaruhi produktivitas produksi tahun ini adalah problem defect, dan terjadi peningkatan defect melebihi target defect perbulan ditahun ini pada bulan Maret sampai bulan Mei 2019. Dalam penelitian ini upaya perbaikan kualitas dilakukan menggunakan metode Statistical Quality Control(SQC). Analisis dilakukan menggunakan beberapa alat dari seven tools yaitu diagram fishbone, diagram pareto, dan peta kendali $\mathrm{P}(P$-Chart $)$. Berdasarkan diagram pareto yang dibuat diketahui defect yang paling dominan yang terjadi di bulan Maret-Mei 2019 adalah jenis dedect Under Cure. Kemudian penyebab-penyebab defect produk tersebut di analisis menggunakan tools diagram Fishbone. Setelah penyebab defect diketahui selanjutnya dibuat rekomendasi perbaikan menggunakan konsep $5 \mathrm{~W}+1 \mathrm{H}$. kemudian dibuat peta kendali P untuk usulan standar defect perhari.
\end{abstract}

Kata Kunci: SQC, Pengendalian Kualitas, Defect, Seven Tools, Produktivitas produksi.

\begin{abstract}
PT. Gajah Tunggal Tbk, is a manufacturer of car and motorcycle tires that always tries to increase production productivity to meet customer-customer demand from automotive companies. Based on data obtained from PT. Gajah Tunggal Tbk., The problem that most affected this year's production productivity was the problem defect, and there was an increase in defects exceeding the monthly defect target this year in March to May 2018. In this study quality improvement efforts were carried out using Statistical Quality Control (SQC) method. The analysis is carried out using several tools from seven tools namely fishbone diagram, pareto diagram, and $P$ control chart $(P$-Chart). Based on the Pareto diagram, it is known that the most dominant defect that occurs in MarchMay 2018 is the type of dedect Under Cure. Then the causes of the product defect were analyzed using Fishbone diagramming tools. After the cause of the defect is known, then a repair recommendation is made using the $5 \mathrm{~W}+1 \mathrm{H}$ concept. then made a $P$ control chart for the proposed standard defect per day.
\end{abstract}

Keywords: SQC, Quality Control, Defect, Seven Tools, Production Productivity. 


\section{PENDAHULUAN}

Perkembangan produksi ban kendaraan bermotor semakin meningkat seiring dengan meningkatnya kebutuhan masyarakat terhadap kendaraan, terutama kendaraan pribadi. Penjualan mobil nasional pada kuartal 1(Q1) 2019 atau priode Januari-Maret tumbuh 2,9 persen, meningkat 8.160 unit dari periode sebelumnya dengan pencapaian 291.912 unit dibandingkan periode yang lalu 283.760 unit (Gaikindo, 2019). Hal tersebut tentunya mendorong perusahaan-perusahaan yang bergerak dibidang manufaktur ban kendaraan untuk meningkatkan produktivitasnya untuk memenuhi permintaan dari customernya. PT. Gajah Tunggal, Tbk. merupakan perusahaan yang bergerak dibidang manufaktur pembuatan ban untuk kendaraan. PT. Gajah Tunggal, Tbk. mengalami peningkatan ekspor, pertumbuhan penjualan perusahaan dicapai di semua segmen dan pasar. Kontribusi terbesar disumbang penjualan ekspor yang tumbuh 14,7 persen. Menghadapi persaingan PT. Gajah Tunggal, Tbk. tentunya harus meningkatkan produktivitas produk OK, Karena perkembangan industri otomotif yang meningkat pesat menuntut perusahaan ban harus lebih giat meningkatkan kuantitas produk OK untuk dapat bersaing dengan perusahaan manufaktur ban lainnya, dan untuk memenuhi permintaan customer-nya. Karena sangat pentingnya kuantitas hasil produk OK untuk mempertahankan serta memenuhi permintaan customer, maka perusahaan harus terus memperhatikan kondisi produktivitas produksi. Hal tersubut juga dilakukan untuk menjaga kepercayaan customer terhadap perusahaan, karena customer adalah harapan perusahaan untuk terus dapat menjual produk yang telah dihasilkan. Karena jika penjualan menurun, akan sangat berdampak buruk terhadap kelangsungan hidup perusahaan. Saat ini terjadi problem produktivitas produksi periode 2019 di PT. Gajah Tunggal, Tbk. divisi Curing Plant D. Unsurunsur yang terdapat di problem produktivitas produksi tersebut meliputi Problem Man, Problem Defect, dan problem Loss Time. Problem Man adalah masalah yang bersumber dari kinerja teanaga kerja dan mempengaruhi produktivitas produksi, Problem Defect adalah masalah yang bersumber dari kerusakan produk dan mempengaruhi produktivitas produksi, dan Problem Loss Time adalah masalah yang bersumber dari hilangnya waktu produksi yang mempengaruhi produktivitas produksi. Data Problem Produktivitas Produksi tersebut seperti pada Gambar 1.

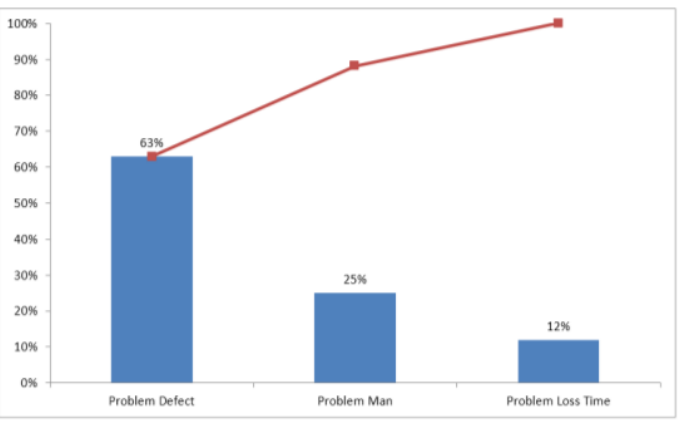

Gambar 1. Data Problem Produktivitas Produksi. Sumber: PT. Gajah Tunggal Tbk (2019).

Berdasarkan grafik data Problem Produktivitas Produksi diatas, problem yang paling signifikan mempengaruhi produktivitas produksi adalah problem defect. Data diatas membuktikan bahwa masalah yang harus dianalisis lebih lanjut oleh penulis adalah masalah pada problem defect, hal tersebut dikuatkan dengan data Actual Defect vs Target defect periode Januari-Mei 2019 seperti pada Gambar 2.

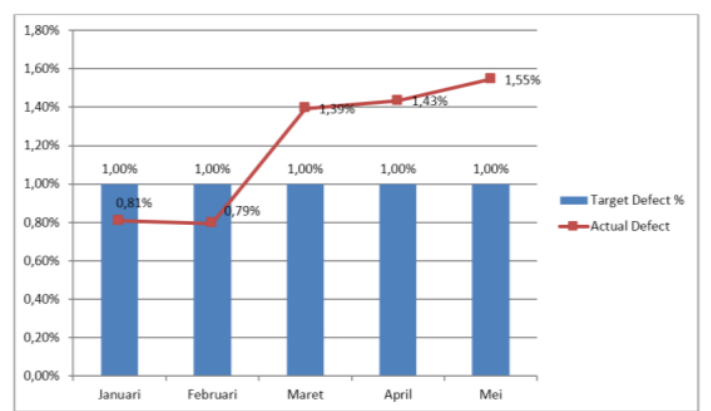

Gambar 2. Grafik Actual Defect vs Target Defect Curing Plant D.

Sumber: PT. Gajah Tunggal, Tbk. Januari-Mei (2019).

Berdasarkan dari data grafik Actual Defect vs Target Defect di Curing Plant D periode 2019 diatas dapat dibuktikan bahwa presentase produk defect mengalami peningkatan di bulan Maret sampai bulan Mei 2019, oleh sebab itu perlu dilakukan pengendalian kualitas hasil produksi di divisi Curing Plant D. Dan juga perlu dianalisa apa yang penyebab defect tersebut. Tujuan penelitian ini mengetahui faktor penyebab Defect produk, memperoleh solusi untuk mencegah defect produk agar tidak kembali meningkat, dan mengetahui jumlah maksimal proporsi defect perhari yang dapat direkomendasikan kepada perusahaan 
agar kualitas produk tetap berada didalam pengendalian.

\section{LANDASAN TEORI \\ 1. Produktivitas}

Produktivitas dapat digambarkan dalam dua pengertian yaitu secara teknis dan financial. Pengertian produktivitas secara teknis adalah pengefesiensian produksi terutama dalam pemakaian ilmu dan teknologi. Sedangkan pengertian produktivitas secara financial adalah pengukuran produktivitas atas output dan input yang telah dikuantifikasi (Rusydiawan \& Krisnadi, 2011).

\section{Kualitas dan Pengendalian Kualitas Produk}

Kualitas adalah totalitas dari karateristik suatu produk yang menunjang kemampuannya untuk memuaskan kebutuhan yang dispesifikasikan atau diterapkan (Gasperz, 2005). Menurut Kotler \& Amstrong (2010), kualitas produk adalah karakteristik dari pro-duk dalam kemampuan untuk memenuhi kebutuhankebutuhan yang telah ditentukan dan bersifat laten. Maka dapat disimpulkan bahwa kualitas produk merupakan suatu produk yang melalui beberapa tahapan proses dengan memperhitungkan nilai suatu produk tanpa adanya kekurangan sedikitpun nilai suatu produk, dan menghasilkan produk yang sesuai dengan harapan tinggi dari pelanggan. Menurut Assauri (2004), pengendalian (pengawasan mutu) adalah kegiatan untuk memastikan apakah kebijakan dalam hal mutu (standar) dapat tercermin dalam hasil akhir, dengan kata lain pengendalian kualitas melakukan usaha untuk mempertahankan mutu atau kualitas dari barang yang dihasilkan agar sesuai dengan spesifikasi produk yang telah ditetapkan berdasarkan kebijakan kepemimpinan perusahaan. Sedangkan menurut Gasperz (2005), pengendalian kualitas adalah teknik dan aktivitas operasional yang digunakan untuk memenuhi standar kualitas yang diharapkan. Berdasarkan beberapa definisi diatas pengendalian kualitas merupakan aktivitas manajemen suatu perusahaan untuk mempertahankan produknya agar tetap berada di batas standar yang telah ditetapkan. Setiap perusahaan mempunyai kebijakan mutunya masingmasing, dalam pengendalian kualitas perusahaan berupaya memastikan apakah hasil akhir pada prosesnya sudah sesuai dengan kebijakan mutu perusahaan.

Menurut Prawirosentono (2007), terdapat beberapa standar kualitas yang ditentukan oleh perusahaan dalam upaya menjaga output barang hasil produksi diantaranya:

a) Standar kualitas bahan baku yang akan digunakan;

b) Standar kualitas proses produksi (mesin dan tenaga kerja yang melaksanakannya);

c) Standar kualitas barang setengah jadi;

d) Standar kualitas barang jadi; dan

e) Standar administrasi, pengepakan dan pengiriman produk akhir tersebut sampai ke tangan konsumen.

Tujuan dari pengendalian kualitas adalah menyidik dengan cepat sebab-sebab terduga atau pergeseran proses sedemikan hingga penyelidikan terhadap proses itu dan tindakan pembetulan dapat dilakkukan sebelum terlalu banyak unit yang tidak sesuai diproduksi (Montgomery D.C. 1990). Pengendalian kualitas produk sering disebut dengan sampling penerimaan (acceptance sampling) yang juga menggunakan teknik pengambilan sampel sebagai cara pengujiannya. Pada pengendalian kualitas produk juga dapat dikelompokan menjadi 2 yaitu: pengendalian kualitas produk data variabel dan pengendalian kualitas produk data atribut. Disamping dikelompokan berdasarkan jenis datanya (variabel dan atribut) pada pengendalian kualitas produk dapat dibedakan berdasarkan jumlah pengambilan sampel, yaitu: sampling pene-rimaan tunggal (single sampling), dan sampling penerimaan jamak (double/multiple sampling).

\section{Pengendalian Kualitas Statistik (Statis- tical Quality Control)}

Statistical Quality Control (Pengendalian Kualitas Statistik) adalah teknik yang digunakan untuk mengendalikan dan mengelola proses baik manufaktur maupun jasa melalui menggunakan metode statistik. Pengendalian kualitas statistik merupakan teknik penyelesaian masalah yang digunakan untuk memonitor, mengendalikan, menganalisis, mengelola dan memperbaiki produk dan proses menggunakan metode-metode statistic. (Montgomery, 2001).

Statistic Quality Control (SQC) merupakan teknik penyelesaian masalah yang digunakan untuk memonitor, mengendalikan, 
mengelola, dan memperbaiki produk dan proses menggunakan metode-metode statistik (Ariani, D. W., 2003)

\section{Peta Kendali P-Chart}

Ariani, D. W., (2003), pengendali proporsi kesalahan $(P$-Chart) dan banyaknya kesalahan (Np-Chart) digunakan untuk mengetahui apakah cacat produk yang dihasilkan masih dalam batas yang disyaratkan, peta pengendali proporsi dan banyak digunakan bila kita memakai ukuran cacat berupa proporsi produk cacat dalam setiap sampel yang diambil. Bila sampel yang diambil untuk setiap kali melakukan observasi jumlahnya sama maka dapat menggunakan peta pengendali proporsi kesalahan (P-Chart) mau-pun banyaknya kesalahan ( $\mathrm{Np}$-Chart). Namun bila sampel yang diambil bervariasi untuk setiap kali melakukan observasi berubah-ubah jumlahnya atau memang perusahaan tersebut akan melakukan $100 \%$ inspeksi maka harus menggunakan peta pengendali proporsi kesalahan $P$-Chart. Batas pengendali bawah (LCL) untuk peta $\mathrm{P}$, yang dinyatakan dalam nilai proporsi atau persentase selalu positif, tidak boleh negatif $(\mathrm{LCL}=0)$.

Apabila dite-mukan nilai negatif dalam perhitungan LCL, maka ditetapkan sama dengan nol. Jadi apa-bila LCL $<0$, maka ditetapkan $L C L=0$. Peta pengendali untuk banyaknya sampel bervariasi yang digunakan hanya peta pengendali proporsi kesalahan (PChart), bukan banyaknya kesalahan (NPChart). Peta pengendali proporsi kesalahan sampel bervariasi memiliki tiga pilihan model, yaitu model harian atau individu, model rata-rata dan model yang dibuat menurut urutan banyaknya sampel berdasarkan pertimbangan perusahaan. Peta kendali $\mathrm{P}$ yang digunakan adalah peta kendali $\mathrm{P}$ model harian/individu, peta kendali model harian/ individu ini dibuat untuk setiap observasi. Keunggulan peta pengendali proporsi kesalahan model harian atau individu ( $p$-chart individu) ini adalah ketepatannya dalam memutuskan apakah sampel berada di dalam atau diluar batas pengendaliannya.

Rumus Peta Kendali P harian/individu adalah sebagai berikut:

$$
\begin{aligned}
& \text { Garis Pusat GP) } \\
& \mathrm{p}=\bar{p}=\frac{\sum_{i=1}^{g} p i}{g}=\frac{\sum_{i=1}^{g} x i}{\sum \text { sampel }}
\end{aligned}
$$

Rumus batas pengendali atas (UCL) dan batas pengendali bawah (LCL):

$$
\begin{aligned}
& \mathrm{BPA} \mathrm{p}=\bar{p}+3 \frac{\bar{p} \sqrt{1-\bar{p}}}{n i} . \\
& \mathrm{BPB} \mathrm{p}=\bar{p}-3 \frac{\bar{p} \sqrt{1-\bar{p}}}{n i} .
\end{aligned}
$$

Dimana:

pi $=$ proporsi kesalahan setiap sampel pada setiap kali observasi.

$\mathrm{xi}=$ banyaknya kesalahan setiap sampel pada setiap kali observasi.

$\mathrm{ni}=$ banyaknya sampel yang diambil pada setiap kali observasi yang selalu bervariasi.

$\mathrm{g}=$ banyaknya observasi.

Rumus revisi peta kendali $\mathrm{P}$ :

Garis Pusat GP) $\mathrm{p}=\bar{p}=\frac{\sum x i-(\text { xi out control })}{\sum n i-(\text { ni out control })}=$

New $C L$

$\mathrm{UCL}=\mathrm{New} \mathrm{CL}+3 \frac{\sqrt{\text { New CL(1-NewCL) }}}{n i}=\mathrm{New}$

$\mathrm{UCL}$

$\mathrm{LCL}=\mathrm{New} \mathrm{CL}-3 \frac{\sqrt{\text { New CL(1-New CL) }}}{n i}=\mathrm{New}$ LCL

Contoh peta kendali P-Chart dapat dilihat dalam Gambar 3.

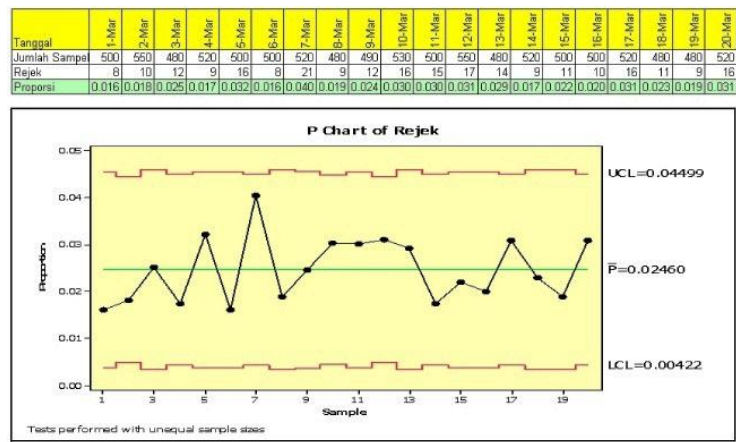

Gambar 3. Contoh P-Chart

Sumber: Nasution (2005)

\section{Capability Process}

Process capability analysis dapat diarti-

kan sebagai suatu analisa untuk mengetahui 
apakah proses kerja yang sedang berjalan memenuhi spesifikasi yang telah ditetapkan. Proses tersebut capable apabila mampu menghasilkan hampir $100 \%$ output sesuai dengan spesifikasi yang sudah ditetapkan. Capability Process adalah suatu kemampuan proses yang mereflesikan derajat keseragaman dalam memproduksi suatu produk. Capability indeks adalah suatu indek yang menggambarkan seberapa jauh proses tersebut dapat memenuhi sepesifikasi yang diharapkan. Indeks untuk mengukur Process Capability analysis antara lain:

a) Cp: Indeks yang menunjukan kemampuan suatu sistem dalam memenuhi spesifikasi limit (limit atas (USL) dan limit bawah (LSL).

b) Perhitungan $\mathrm{Cp}$ menggunakan estimasi sigma dan dapat digunakan untuk menunjukan potensi suatu sistem dalam memenuhi spesifikasi.

c) Dalam Cp, tidak memperhitungkan ratarata proses, hanya berfokus pada spred (persebaran data).

d) Cpk: indeks yang menunjukan seberapa baik suatu sistem dapat memenuhi spesifikasi limit.

e) Perhitungan Cpk menggunakan estimasi sigma dan dapat digunakan untuk menunjukan potensi sistem dalam memenuhi spesifikasi.

f) Dalam Cpk, rata-rata proses diperhitungkan.

Indeks Kapabilitas Proses dapat dihitung seperti dalam rumus berikut:

a) Hitung indeks $\mathrm{Cp}$

$$
\mathrm{Cp}=\frac{U S L-L S L}{6 S}
$$

dimana $\mathrm{S}=\sqrt{\frac{\left(\mathrm{N} x \sum x i^{2}\right)-\left(\sum x i\right)^{2}}{\mathrm{~N}(\mathrm{~N}-1)}}$

Kriteria penilaian: Jika $\mathrm{Cp}<1,00$ maka kapabilitas proses rendah.

b) Hitung indeks $\mathrm{Cpk}$

$\mathrm{Cpk}=\{\mathrm{CPU} ; \mathrm{CPL}\}$

dimana:

$\mathrm{CPU}=\frac{U S L-X}{3 S}$ dan $\mathrm{CPL}=\frac{X-L S L}{3 S}$

Kriteria penilaian: Jika $\mathrm{Cpk}<1$, maka proses menghasilkan produk yang tidak sesuai dengan spesifikasi.

\section{METODE PENELITIAN DAN PENG- OLAHAN DATA}

Data penelitian menggunakan data sekunder yang diperoleh dari perusahaan yaitu data penyebab problem produktifitas dan data $d e$ fect aktual yang terjadi selama periode MaretMei 2019 seperti terlihat pada Gambar 1.1 dan Gambar 1.2 diatas.

Dalam melakukan pengolahan data yang diperoleh dari perusahaan, maka digunakan alat bantu statistik yang terdapat pada Statistical Quality Control (SQC). Adapun langkah-langkahnya adalah sebagai berikut:

\section{Mengumpulkan Data Menggunakan Check Sheet}

Data yang diperoleh dari perusahaan terutama dari departemen Curing plant $\mathrm{D}$, data tersebut berupa laporan produksi harian yang terdapat jumlah produk yang diproduksi perhari beserta jumlah defect dan jenis-jenis defect bulan Januari-Mei 2019 pada Tabel 1.

Dari data tabel check sheet diketahui ada tiga jenis defect pada produk yaitu Open Mold (kerusakan ban berupa ban membelah dua), Under Cure (kerusakan ban berupa ban tidak terbentuk menjadi ban, cendrung masih berupa green tire (metrial curing tire) tetapi bentuknya sudah tidak layak karena komponen bit/kawatnya sudah keluar, kemudian defect jenis Blown (kerusakan ban berupa terdapat gelembung pada bagian ban setelah di curing.

Tabel 1. Kumulatif Check sheet hasil produksi dan defect Januari-Mei 2019

\begin{tabular}{|l|r|r|r|r|r|r|r|}
\hline \multirow{2}{*}{ Bulan } & \multirow{2}{*}{$\begin{array}{c}\text { Jumlah } \\
\text { Produksi }\end{array}$} & $\begin{array}{c}\text { Open } \\
\text { Mold }\end{array}$ & $\begin{array}{c}\text { Under } \\
\text { Cure }\end{array}$ & Blown & $\begin{array}{c}\text { Total } \\
\text { Defect }\end{array}$ & $\begin{array}{c}\% \\
\text { Defect/ } \\
\text { Bulan }\end{array}$ & $\begin{array}{c}\% \\
\text { Target } \\
\text { Defect }\end{array}$ \\
\hline Januari & 900034 & 790 & 4188 & 2310 & 7288 & 0.81 & 1.00 \\
\hline Februari & 1007471 & 2541 & 2754 & 2707 & 8002 & 0.79 & 1.00 \\
\hline Maret & 760610 & 1572 & 5394 & 3631 & 10597 & 1.39 & 1.00 \\
\hline April & 714377 & 2168 & 4859 & 3212 & 10239 & 1.43 & 1.00 \\
\hline Mei & 712634 & 2605 & 4668 & 3739 & 11012 & 1.55 & 1.00 \\
\hline
\end{tabular}

Sumber: PT. Gajah Tunggal, Tbk Plant D, Juni 2019

\section{Menentukan Prioritas Analisis}

Untuk menentukan prioritas analisis, maka perlu dilakukan stratifikasi data. Berdasarkan fenomena pada bab 1 diketahui bahwa problem produktivitas produksi yang paling mempengaruhi produktivitas produksi di Plant D yaitu problem defect. Untuk lebih jelasnya dapat dilihat pada Gambar 4. 


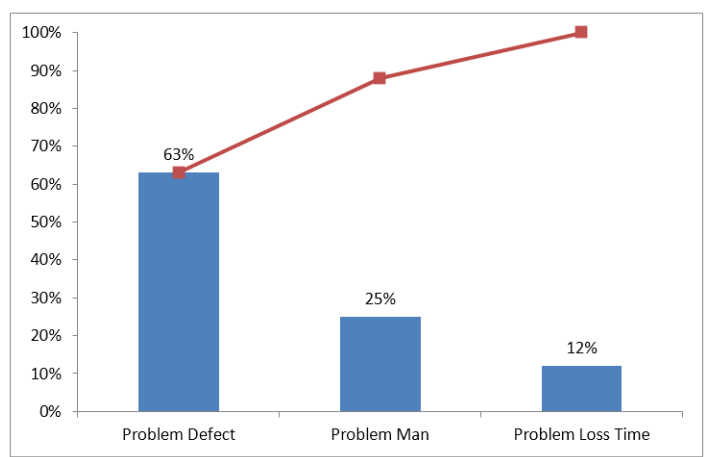

Gambar 4. Problem produktivitas produksi periode 2019 Sumber: PT. Gajah Tunggal, Tbk. Maret-Mei 2019

Berdasarkan stratifikasi data problem produktivitas produksi, diketahui bahwa problem defect yang akan menjadi prioritas analisis karena problem tersebut yang paling dominan mempengaruhi produktivitas produksi.

\section{Menganalisis Penyebab Defect Dengan Fishbone Diagram}

Setelah diketahui bahwa jenis-jenis $d e$ fect produk yang terjadi di Curing Plant D yaitu defect Open Mold, defect Under Cure, dan defect Blown, kemudian dilakukan analisis penyebab ketiga defect tersebut dengan teknik wawancara yang dilakukan kepada beberapa karyawan yang terkait. Setelah itu digunakan diagram fishbone untuk mendeskripsikan penyebab defect. Pertama dilakukan analisis penyebab defect Open Mold, kedua dilakukan analisis defect Under Cure, dan terakhir dilakukan analisis penyebab defect Blown. Adapun hasil analisis penyebab defect terlihat pada Gambar 5.

a) Analisis penyebab Open Mold

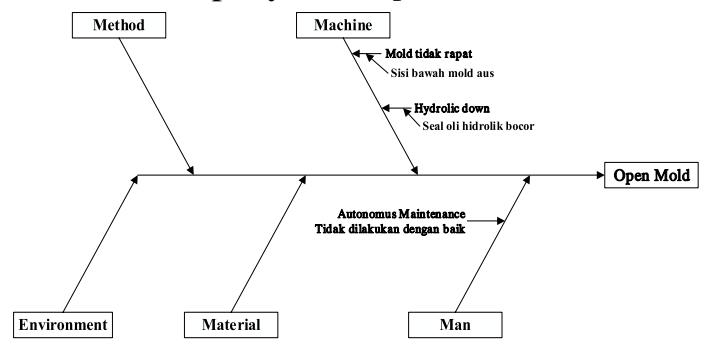

Gambar 5. Diagram Fishbone penyebab defect Open Mold.

Sumber: Data diolah, 2019 b) Analisis penyebab UC/Under Cure

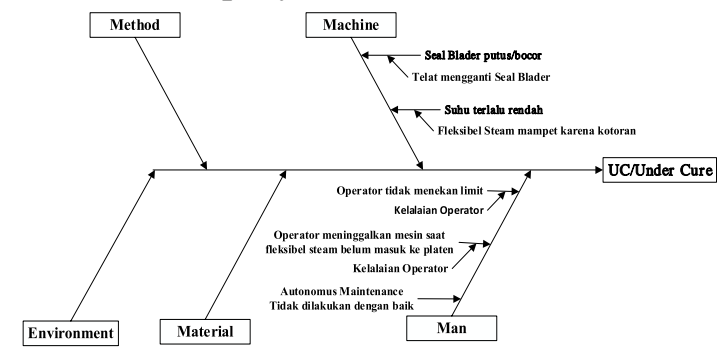

Gambar 6. Diagram fishbone penyebab UC (under cure). Sumber: Data diolah, 2019.

c) Analisis Penyebab jenis Blown

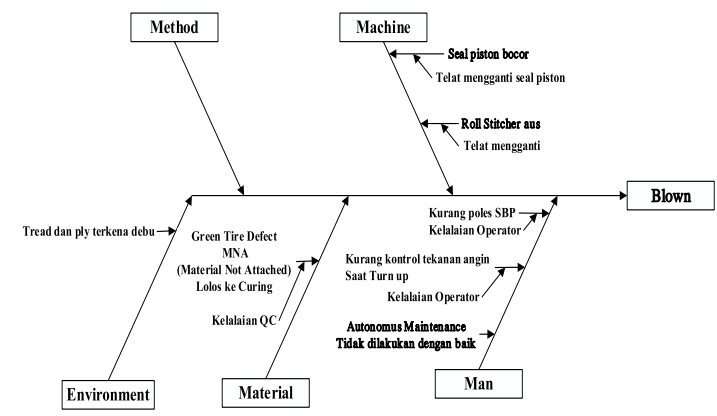

Gambar 7. Diagram Fishbone penyebab Blown. Sumber: Data diolah, 2019.

(1) Berdasarkan hasil analisis diagram fishbone pada Gambar 5, maka didapatkan akar penyebab Open Mold yaitu: 1) Sisi bawah mold aus; 2) Seal oli hidrolik bocor; dan 3) Autonomus Maintenance tidak dilakukan dengan baik

(2) Berdasarkan hasil analisis diagram fishbone pada Gambar 6, maka didapat-kan akar penyebab UC (under cure) yaitu: 1) Kelalaian operator tidak menekan limit saat curing; 2) Kelalian Operator meninggalkan mesin ketika fleksibel steam belum masuk ke platen; 3) Telat mengganti seal blader; dan 3) Fleksibel Steam mampet karena kotoran.

(3) Berdasarkan hasil analisis diagram fishbone pada Gambar 7, maka didapatkan akar penyebab Blown yaitu: 1) Telat mengganti seal piston; 2) Telat mengganti roll sticher; 3) Kelalaian operator dalam mengatur tekanan angin roll sticher; 3) Kelalaian QC Building; dan Ply dan Ttread terkena debu sebelum di beri lem.

\section{Membuat Pareto Diagram Jenis Defect Paling Dominan}

Grafik pareto diatas diketahui bahwa jenis 
defect yang paling dominan terjadi selama bulan Januari sampai bulan Mei 2019 adalah jenis defect under cure.

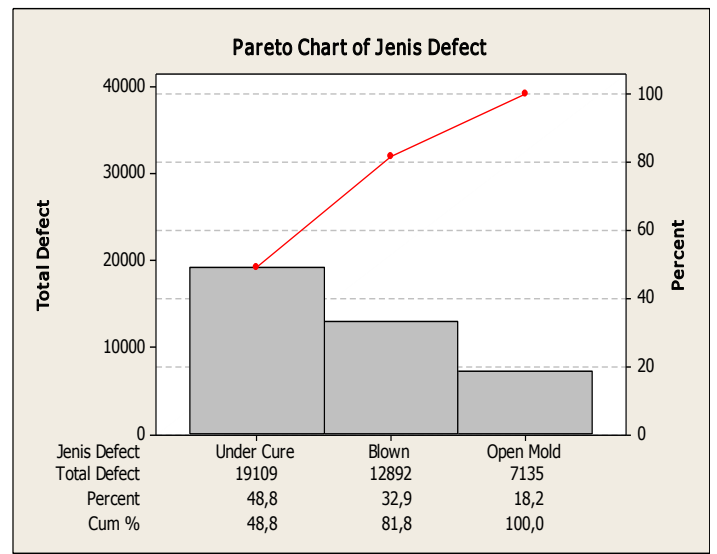

Gambar 11. Pareto jenis defect dominan.

Sumber: Data diolah, 2019.

\section{Membuat Rekomendasi Usulan Per- baikan}

Berdasarkan akar penyebab defect yang telah diketahui diatas maka selanjutnya dapat dibuat rekomendasi perbaikan mennggunakan konsep $5 \mathrm{~W}+1 \mathrm{H}$. Rekomendasi perbaikan dapat dilihat pada Tabel 2-Tabel 3.

Tabel 2. Rekomendasi perbaikan menggunakan $5 \mathrm{~W}+1 \mathrm{H}$

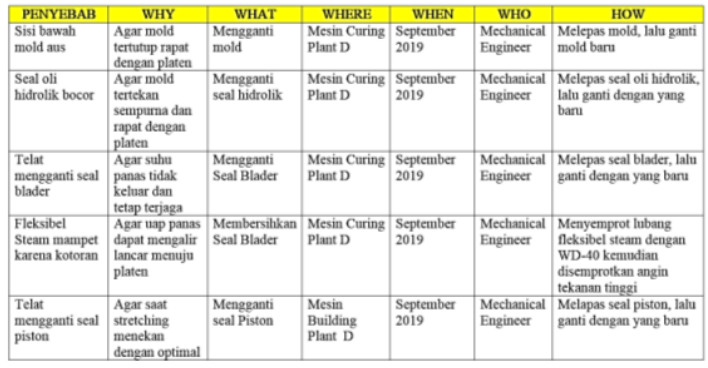

Sumber: Data diolah, 2019.

Tabel 3. Lanjutan Rekomendasi perbaikan menggunakan $5 \mathrm{~W}+1 \mathrm{H}$.

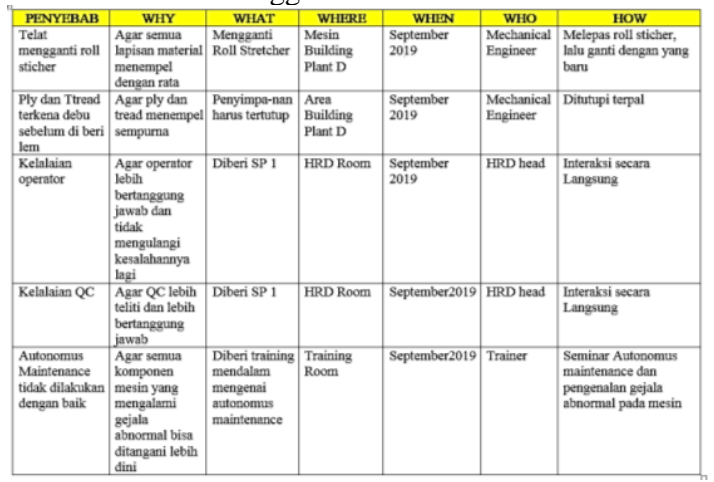

Sumber: Data diolah, 2019.

\section{Membuat peta kontrol P (p-chart)}

Peta kendali P (P-chart) digunakan untuk membuat standarisasi jumlah defect mak- simal produk defect. Tujuannya adalah untuk mengetahui berapa maksimal jumlah proporsi produk defect perhari agar tetap berada dalam batas pengendalian. Peta kendali $\mathrm{P}$ dibuat menggunakan software minitab'16. Untuk membuat peta kendali $\mathrm{P}$ sebagai acuan untuk membuat standar proporsi defect perhari maka digunakan data hasil produksi beserta jumlah defect dan proporsi defect harian dari bulan Januari-Februari 2019 karena pada bulan tersebut mengalami persentase defect yang paling rendah/yang berada dibawah 1,00\% (dibawah batas maksimal yang ditetapkan perusahaan).

a) P-chart Produksi Januari 2019

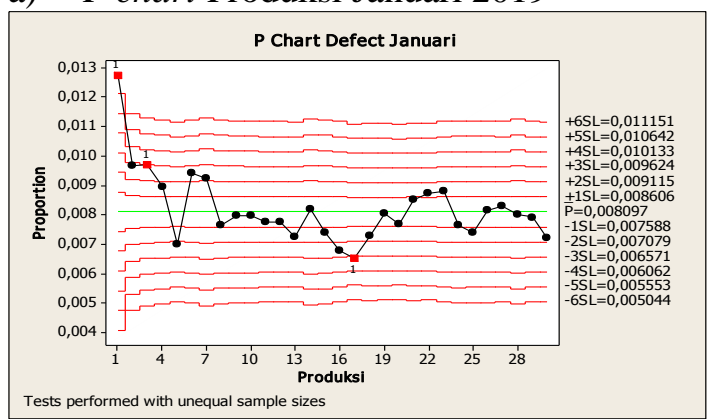

Gambar 12. P-chart Defect Januari 2019.

Sumber: Data diolah (2019).

Berdasarkan Peta kendali P diatas diketahui bahwa masih ada data-data yang berada diluar kontrol, maka perlu dilakukan revisi. Untuk lebih jelasnya mengenai data-data yang berada diluar kontrol tersebut dapat dilihat pada Gambar 13.

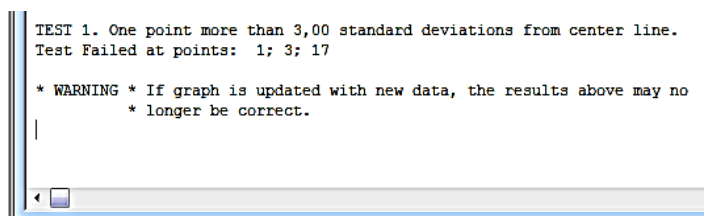

Gambar 13. Data-data diluar kontrol $P$-chart Januari 2019.

Sumber: Data diolah (2019).

Berdasarkan gambar diatas diketahui bahwa data-data yang keluar kontrol berada di subgrup 1,3, dan 17, maka untuk merevisi peta kendali $\mathrm{P}$ data-data yang berada diluar kontrol tersebut harus dihilangkan dan kemudian membuat peta kendali $\mathrm{P}$ yang baru. 


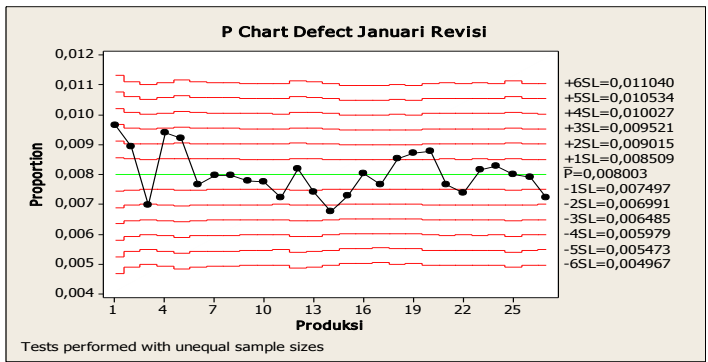

Gambar 14. Revisi P-Chart defect Januari 2019. Sumber: Data diolah (2019).

Berdasarkan Peta kendali P diatas diketahui sudah tidak ada data-data yang berada diluar kontrol, maka tidak perlu dilakukan revisi kembali.

Selanjutnya dilakukan perhitungan $\mathrm{Ca}$ pability Pocess untuk mengetahui nilai $\mathrm{Cp}$ dan Cpk sebagai indikator seberapa besar sebuah process mampu memenuhi spesifikasi. Untuk mengetahui nilai $\mathrm{Cp}$ dan Cpk pada produksi di bulan Januari dapat di lihat pada Gambar 4.15

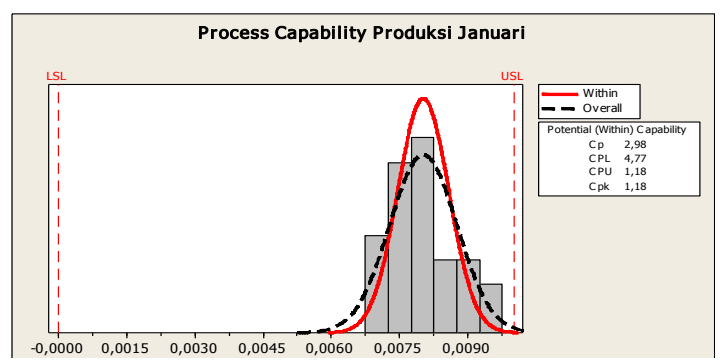

Gambar 15. Capability produksi Januari 2019.

Sumber: Data diolah (2019).

Berdasarkan gambar diatas diketahui bahwa nilai Cp pada produksi di bulan Januari adalah 2,98 dan nilai Cpk pada produksi di bulan Januari adalah1,18.

Selanjutnya menganalisis nilai \% Defective seperti pada Gambar 16.

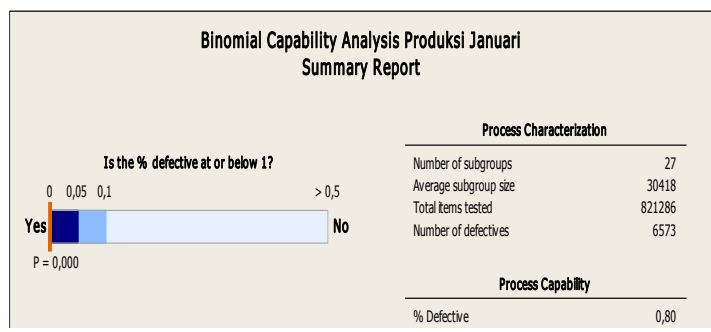

Gambar 16. Capability Analysis Produksi Januari 2019. Sumber: Data diolah (2019).

Berdasarkan gambar diatas diketahui bahwa nilai \% Defective: $0,80 \%$.

b) P-chart Produksi Februari 2019

Gambar 4.17 Peta kendali P-Chart defect bulan Februari 2019 sebagai berikut:

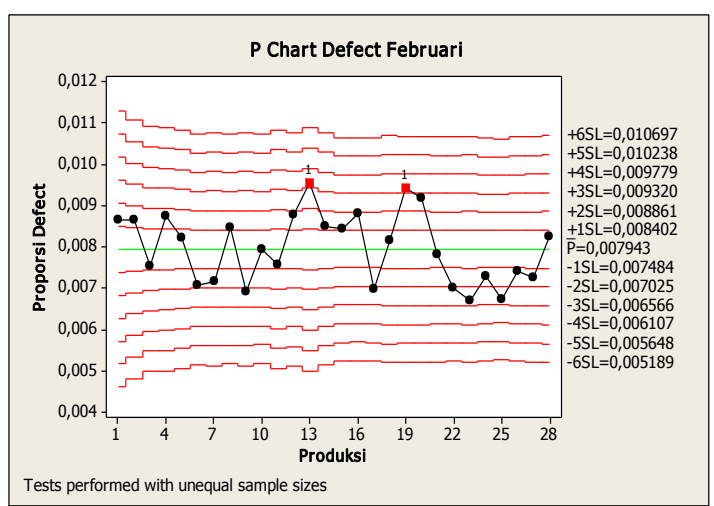

Gambar 17. P-chart defect Februari 2019.

Sumber: Data diolah, 2019.

Berdasarkan peta kendali diatas masih ada data yang berada diluar batas atas. Untuk mengetahui lebih jelasnya mengenai bagian mana saja data-sata yang berada diluar kontrol dapat dilihat pada lembar session pada minitab seperti pada Gambar 18.

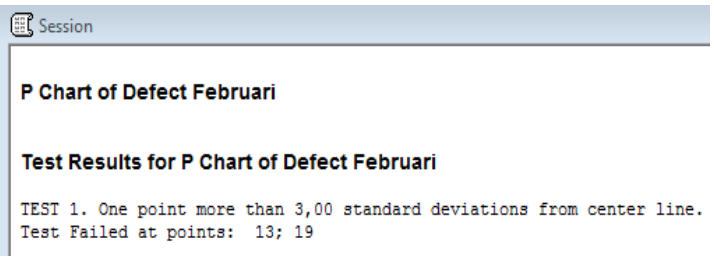

Gambar 18. Data-data diluar kontrol P-chart Februari 2019.

Sumber: Data diolah, 2019.

Berdasarkan Gambar 18, karena masih terdapat data-data yang berada diluar kontrol, maka perlu dilakukan revisi Peta Kendali $\mathrm{P}$ dilakukan dengan menghilangkan data yang berada diluar kontrol dan membuat peta kendali $\mathrm{P}$ baru berdasarkan jumlah subgrup baru.

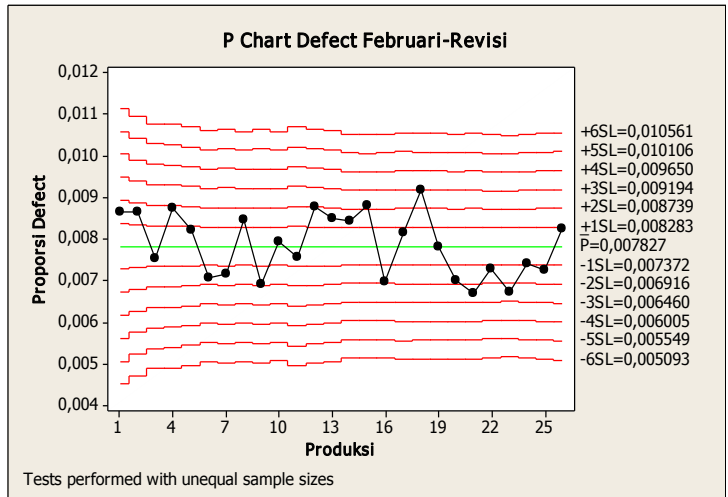

Gambar 19. Revisi P-chart defect Februari 2019.

Sumber: Data diolah (2019).

Berdasarkan hasil Peta kendali $\mathrm{P}$ revisi pada Gambar 19 diketahui sudah tidak ada 
data-data yang berada diluar kontrol.

Selanjutnya dilakukan perhitungan Capability Pocess untuk mengetahui nilai $\mathrm{Cp}$ dan Cpk sebagai indikator seberapa besar sebuah process mampu memenuhi spesifikasi. Untuk mengetahui nilai $\mathrm{Cp}$ dan $\mathrm{Cpk}$ pada produksi di bulan Februari dapat di lihat pada Gambar 20.

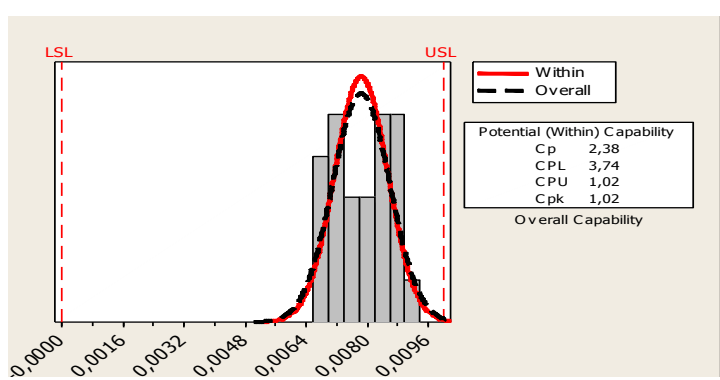

Gambar 20. Capability produksi Februari 2019 Sumber: Data diolah (2019)

Berdasarkan Gambar 20. diketahui bahwa nilai $\mathrm{Cp}$ pada produksi di bulan Februari adalah 2,38 dan nilai Cpk pada produksi di bulan Februari adalah 1,02.

Selanjutnya menganalisis nilai Z. Bench dan \%Defective seperti pada Gambar

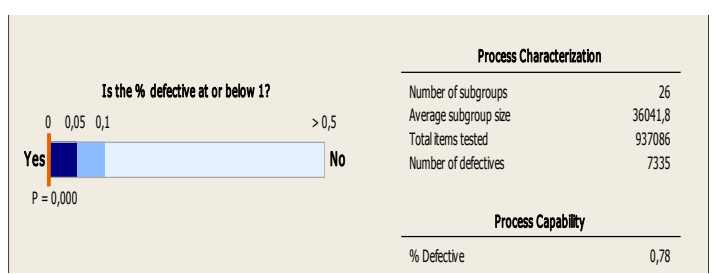

Gambar 21. Capability Analysis produksi Februari 2019. Sumber: Data diolah (2019).

Berdasarkan Gambar 21 diketahui bahwa nilai \% Defective: $0,78 \%$.

\section{HASIL DAN KESIMPULAN \\ 1) Kesimpulan}

Berdasarkan hasil pengolahan data kendali $\mathrm{P}$ yang dibuat berdasarkan data produksi dan proporsi defect bulan Januari dan Februari menghasilkan beberapa perbandingan seperti pada Tabel 4.
Tabel 4. Perbandingan Capability bulan Januari vs

\begin{tabular}{|c|c|c|}
\cline { 2 - 3 } \multicolumn{1}{c|}{} & $\begin{array}{c}\text { Produksi } \\
\text { Januari }\end{array}$ & $\begin{array}{c}\text { Produksi } \\
\text { Februari }\end{array}$ \\
\hline Cp & 2,98 & 2,38 \\
\hline Cpk & 1,18 & 1,02 \\
\hline
\end{tabular}

Sumber: Data diolah (2019).

Berdasarkan tabel diatas diketahui bahwa pada bulan Januari jika dilakukan revisi peta kendali, produksi di bulan Januari mampu menghasilkan total defect $0,80 \%$ atau $20 \%<$ $1 \%$ (Target defect perusahaan). Dan pada bulan Februari jika dilakukan revisi peta kendali, produksi di bulan Februari mampu menghasilkan total defect $0,78 \%$ atau $22 \%<1 \%$ (Target defect perusahaan). Jika perusahaan ingin membandingkan apakah bulan Maret 2019 dan setersunya \% Defective dan sebaran atau variasi proporsi defect dan kemampuan memenuhi spesifikasi sudah lebih baik atau belum maka acuannya adalah nilai $\mathrm{Cp}$ pada produksi di bulan Maret 2019 dan setersunya harus lebih besar dari 2,98 (nilai Cp produksi Januari 2019), kemudian nilai Cpk harus lebih besar dari: 1,18 (nilai Cpk produksi Januari 2019). Kemudian nilai \% Defective harus lebih rendah dari $0,78 \%$ (nilai \% Defective produksi Februari 2019).

\section{2) Rekomendasi standar proporsi defect perhari}

Sebagai acuan untuk standar proporsi defect perhari agar perusahaan mampu mengendalikan produksi dan defect yang lebih baik maka proporsi defect perhari maksimal/tidak boleh melebihi 0,0078 atau $0,78 \%$, dan akan lebih baik lagi jika proporsi defect perhari lebih rendah dari 0,0078 atau $0,78 \%$.

\section{DAFTAR PUSTAKA}

Andersson, R., Hilletofth, P., Manfredsson, P., \& Hilmola, O. P. (2014). Lean Six Sigma strategy in telecom manufacturing. Industrial Management \& Data Systems, 114 (6), 904-921.

Antony, J., \& Taner, T. (2003). A conceptual framework for the effective implemen- 
tation of statistical process control. Business Process Management Journal, 9(4), 473-489.

Ariani , D. W. (2003). Pengendalian Kualitas Statistik. Yogyakarta: Penerbit Andi

Assauri, S. Manajemen Pemasaran. 2007. PT Raja Grafindo Persada: Jakarta.

Bakhtiar, S., Tahir, S., \& Hasni, R. A. (2013). Analisa pengendalian kualitas dengan menggunakan metode statistical quality control (SQC). IEJ, 2(1).

Chandra, J. C. (2013). Implementasi Pengendalian Kualitas Dengan Menggunakan Metode Statistik Pada PT Diantrijaya Utama Mukti Di Surabaya. CALYPTRA, 2(2), 1-17.

Ekoanindiyo, F. A. (2015). Pengendalian Cacat Produk dengan Pendekatan Six Sigma. Jurnal Ilmiah Dinamika Teknik, 8(1).

Eriskusnadi. wordpress.com. (2012) - Tentang 7 Basic Quality Tools - Selasa, 10 Juli 2019

https://eriskusnadi.wordpress.com/2012/ 09/29/about-7-basic-quality-tools/

Faizuddin, M., Poniman, P., \& Jumi, J. (2016). Analisis Pengendalian Kualitas Produk Dalam Upaya Mengendalikan Tingkat Kerusakan Produk Ekspor di PT. Asia Pacific Fibers, tbk Kaliwungu. jobs, 1(1).

Gaspersz, Vincent. (2005). Total Quality Management. Jakarta: PT. Gramedia Pustaka Utama.

Halim Lim, S. A., Antony, J., Arshed, N., \& Albliwi, S. (2017). A systematic review of statistical process control implementation in the food manufacturing industry. Total Quality Management \& Business Excellence, 28(1-2), 176-189.

Hargo, H. D. (2013). Implementasi Metode Pengendalian Kualitas pada Proses Produksi Tali Rafia Hitam dengan Menggunakan Metode Statistik di UD Kartika Plastik Jombang. Calyptra, 2(1), 1-19.

Kaban, R. (2014). Pengendalian Kualitas Kemasan Plastik Pouch Menggunakan Statistical Procces Control (SPC) di PT.
Incasi Raya Padang. Jurnal Optimasi Sistem Industri, 13(1), 518-547.

Khomah, I., \& Rahayu, E. S. (2016). Aplikasi Peta Kendali p sebagai Pengendalian Kualitas Karet di PTPN IX Batujamus/Kerjoarum. AGRARIS: Journal of Agribusiness and Rural Development Research, 1(1), 12-24.

Kotler \& Keller, (2009). Manajemen Pemasaran Jilid 2, Edisi Ketiga Belas, Terjemahan Bob Sabran, Mm. Jakarta: Salemba Empat

Momon, A. (2011). Implementasi Sistem PeNgendalian Kualitas Dengan Metode Seven Tools Terhadap Produk Shotblas Pada Proses Cast Wheel di PT. XYZ. Majalah Ilmiah SOLUSI, 10(21).

Montgomery, D. C. (2001). Introduction to statistical quality control. Fourth Edition. Canada: John Wiley \& Sons, Inc

Opit, P. F., Samadhi, T. A., \& Singal, Y. M. (2008). Penerapan Six Sigma Untuk Peningkatan Kualitas Produk Bimoli Classic (Studi Kasus: PT. Salim Ivomas Pratama-Bitung). J@ TI UNDIP: Jurnal Teknik Industri, 3(1), 17-25.

Pakki, G., Soenoko, R., \& Santoso, P. B. (2014). Usulan Penerapan Metode Six Sigma Untuk Meningkatkan Kualitas Klongsong (Studi Kasus Industri Senjata). Journal of Engineering and Management in Industrial System, 2(1).

Pires de Souza, R., Roberto Hékis, H., Ambrósio Bezerra Oliveira, L., Viegas Queiroz, J., Barbosa Pereira Queiroz, F. C., \& Alexsandro de Medeiros Valentim, R. (2013). Implementation of a Six Sigma project in a $3 \mathrm{M}$ division of Brazil. International Journal of Quality \& Reliability Management, 30(2), 129-141

Prawirosentono, Suyadi. (2007). Manajemen Operasi (Operations Management): Analisis Dan Studi Kasus (Edisi 4) Penerbit Bumi Aksara, Jakarta

Rahmandinata, F., Hamid, L., \& Marpaung, R. (2015). Pengendalian Mutu Produksi Ikan Salai Patin Di Sentra Pengolahan Pasca Panen Dengan Metode Sqc (Statistik Quality Control) di Desa Koto Mesjid 
Kecamatan Koto Kampar Kabupaten Kampar Provinsi Riau. Jurnal Online Mahasiswa Fakultas Ekonomi Universitas Riau, 2(2), 1-11.

Rully, T., \& Nurrohman, A. (2013). Peranan Pengendalian Mutu Dengan Menggunakan Metode Sqc Dan Diagram Sebab Akibat Guna Mengurangu Produk Cacat Pada Ozi Aircraft Models. JIMFE| Jurnal Ilmiah Manajemen Fakultas Ekonomi, 5(2), 62-69.

Rusydiawan, I., \& Krisnadi, I. (2013). Meningkatkan Produktivitas Produksi dengan Optimalisasi Sistem Infrastruktur TI Menggunakan Metoda IT Balanced Scorecard. InComTech, 2(1), 89-106.

Sofyan, A. (2004). Manajemen Produksi dan Operasi Edisi Revisi 2004". Lembaga Penerbit FE UI, Jakarta.

Solihudin, M., \& Kusumah, L. H. (2017). Analisis Pengendalian Kualitas Proses Produksi Dengan Metode Statistical Process Control (SPC) di PT. Surya Toto Indonesia, TBK. Prosiding SENIATI, 3(2), 31-1.
Srinivasu, R., Reddy, G. S., \& Rikkula, S. R. (2011). Utility of quality control tools and statistical process control to improve the productivity and quality in an industry. International Journal of Reviews in Computing, 5, 15-20.

Tisnowati, H., Hubeis, M., \& Hardjomidjojo, H. (2010). Analisis pengendalian mutu produksi roti (Kasus PT. AC, Tangerang). MANAJEMEN IKM: Jurnal Manajemen Pengembangan Industri Kecil Menengah, 3(1), 51-61.

Tjiptono, F., \& Diana, A. (2003). TQM Edisi Revisi.

Wibawati, W., \& Estuningtyas, I. (2013). Analisis Pengendalian Kualitas Produk Labelstock Menggunakan Diagram Kontrol Kernel di PT." X". Jurnal Sains dan Seni ITS, 2(2).

Wisnubroto, P., \& Rukmana, A. (2015). Pengendalian Kualitas Produk dengan Pendekatan Six Sigma dan Analisis Kaizen Serta New Seven Tools sebagai Usaha Pengurangan Kecacatan Produk. Jurnal Teknik Industri, 8(1), 65-74. 